\title{
AVALIAÇÃO PRELIMINAR DE PERDAS NA PRODUÇÃO DEVIDAS A NOVA ANORMALIDADE DO ALGODOEIRO NO BRASIL ( ${ }^{1}$ )
}

\author{
EDERALDO JOSÉ CHIAVEGATO $\left({ }^{2}\right)$, MILTON GERALDO FUZATTO $\left({ }^{2}\right)$, \\ EDIVALDO CIA $\left(^{2,4}\right)$ e ARMANDO PETTINELLI JÚNIOR $\left({ }^{3}\right)$
}

\begin{abstract}
RESUMO
Foram determinadas, em condições de campo, as perdas na produção do algodoeiro devidas a nova anormalidade, de causa desconhecida, à qual os autores se referem como "murchamento avermelhado". Mediante marcação de plantas afetadas - excluídas as que já se encontravam secas ou mortas - realizadas aos cem dias de idade, estabeleceram-se três grupos, de acordo com a intensidade crescente de sintomas, cujas produçōes foram comparadas com a do grupo de plantas aparentemente normais. Diferenças altamente significativas foram verificadas entre os grupos e, mediante análise de regressão $\left(\mathrm{r}^{2}=0,996\right)$, perdas esperadas de 16,33 e $49 \%$ foram estimadas na produção média das plantas, à medida que crescia a severidade dos sintomas. Embora rebrotas ou aparente normalizaçāo da folhagem tenham sido observadas, sobretudo nas plantas com sintomas menos graves, os resultados indicam que isso não pode ser considerado, do ponto de vista da produção de algodão, uma efetiva recuperação das plantas afetadas. Os dados sugerem uma estabilidade do potencial de dano, ao nível de planta - uma vez manifestado o problema - em cada uma das categorias de sintomas analisadas.
\end{abstract}

Termos de indexação: algodoeiro, "murchamento avermelhado", perdas na produção.

(1) Recebido para publicação em 29 de junho e aceito em 3 de novembro de 1994.

${ }^{2}$ ) Seção de Algodão, Instituto Agronômico (IAC), Caixa Postal 28, CEP 13001-970, Campinas (SP).

$\left({ }^{3}\right)$ Estação Experimental de Tatuí (IAC).

$\left({ }^{4}\right)$ Com bolsa de pesquisa do CNPq. 


\title{
ABSTRACT \\ PRELIMINARY EVALUATION OF YIELD LOSSES DUE TO A NEW ABNORMALITY AFFECTING COTTON CROPS IN BRAZIL
}

\begin{abstract}
Cotton yield losses due to a new adversity of unknown cause, refered by the authors as "reddish wilting", were evaluated under field conditions at State of São Paulo, Brazil. Excepting those already dried or dead, affected plants, with about 100 days of age, were marked, according to three degrees of symptoms severity, in order to compare their average yield to that of apparently normal plants. Highly significant differences were verified among the groups and hased on a linear regression analysis $\left(r^{2}=0.996\right)$ expected losses of 16,33 and $49 \%$ were estimated, respectively, for the increasing symptoms intensity classes of affected plants. Although foliage restauration was observed, the results indicated that this can not be considered, from the cotton production viewpoint, as an effective recuperation of the affected plants. Otherwise, the data suggest stability of potential damage, at plant level once the problem is manifested - in each one of de symptom categories analysed.
\end{abstract}

Index terms: cotton, "reddish wilting", yield losses.

No ano agrícola 1993/94, numerosos algodoais no Estado de São Paulo - assim como em toda a região meridional de cultivo no País - foram afetados por uma anormalidade inédita ou, pelo menos, não relatada, formalmente, em nosso meio. De causa desconhecida até o momento (maio de 1994), o problema tem sido denominado "vermelhão", impropriamente, uma vez que não se trata da virose descrita com esse nome por Costa \& Sauer (1954), de ocorrência comum nas lavouras regionais. Em vista disso, os autores preferem referir-se a ele, ainda que provisoriamente, como "murchamento avermelhado" do algodoeiro.

Com incidência distribuída por área geográfica ampla e, na observação dos autores, altamente associada à infestação das lavouras por pulgão, a anomalia foi constatada em plantas com idades desde 40 até 80 dias aproximadamente. Os principais sintomas apresentados pelas plantas, em condiçôes de campo, são: folhas com epinastia (dobradas para baixo, nas proximidades e paralelamente às duas nervuras maiores laterais), inicialmente com coloração amarelada e, depois, com avermelhamento (o avermelhado pode-se manifestar também nos pecíolos e no caule); murchamento in tenso de algumas ou de todas as folhas; temperatura mais elevada das folhas afetadas, em relação às normais, da mes- ma ou de outra planta, perceptível mediante contato manual; queda ou seca dos órgãos reprodutivos e, nos casos mais graves, seca ou morte completa das plantas, poucos dias após o aparecimento dos sintomas. Nos casos mais severos, principalmente, observa-se forte necrose de raízes, a partir das extremidades. Uma característica freqüente é a incidência em trechos de 0,5 a $1,0 \mathrm{~m}$, na extensão da linha de plantio, onde todas as plantas são afetadas, intercalados a espaços com plantas normais. O problema tem sido constatado tanto em plantas isoladas como em reboleiras, em áreas extensas e até mesmo em toda a gleba. Plantas afetadas podem rebrotar ou readquirir aparência normal, nos casos menos graves, o que tem sido interpretado como possível recuperação das lavouras atingidas.

O presente trabalho resultou de estudo preliminar, realizado com o objetivo de verificar a hipótese de recuperação mencionada e, por extensão, dos eventuais danos à produção das plantas atacadas.

\section{Material e Métodos}

O estudo foi realizado na Estação Experimental de Tatuí, do Instituto Agronômico (IAC), em campo de aumento de sementes da variedade comercial 
IAC 20. Em gleba com incidência média-forte da anormalidade, segundo padrões antes observados, foi escolhida área com cerca de $3.000 \mathrm{~m}^{2}$, relativamente uniforme com respeito ao porte das plantas e ao estande. A cultura tinha aproximadamente cem dias de idade, a contar da emergência das plantas.

Mediante etiquetas diferenciadoras, marcaram-se ao acaso, de acordo com a intensidade dos sintomas apresentados, plantas pertencentes às seguintes categorias: nota 1 - sem sintomas; nota 2 - com, pelo menos, uma e, no máximo, duas folhas com início de epinastia e de coloração amarelada, bronzeada ou avermelhada; nota 3 - duas a três folhas revelando epinastia acentuada, murchamento e coloração característica, mas sem redução aparente do porte das plantas; nota 4 - plantas com todas ou com a maioria das folhas mostrando sintomas, desenvolvimento comprometido e queda acentuada ou seca de órgãos reprodutivos, porém sem apresentar caule e folhas secas. Plantas secas, embora passíveis de, eventualmente, rebrotar, não foram marcadas, tendo sido consideradas inviáveis, do ponto de vista agrícola.

Do modo exposto, foram marcadas 15 plantas de cada categoria, cuidando para que não estivessem isoladas ou beneficiadas por falhas contíguas, bem como afetadas por outras anormalidades. Estando a totalidade dos frutos abertos e evitando novamente considerar plantas sujeitas a outras anomalias, foram as plantas colhidas separadamente e o algodão em caroço, seco em estufa e pesado.

\section{Resultados e Discussão}

Do total de plantas marcadas, oito não foram localizadas e, após análises preliminares, elimiraram-se duas outras, uma no grupo 2 e outra no 4, por suas produções substancialmente menores do que o limite inferior do intervalo de confiança, a $1 \%$, das respectivas médias. Com isso, as análises definitivas levaram em conta 14 plantas nota 1 e 12 plantas em cada uma das demais classes. Como as variâncias nos quatro grupos se mostrassem bastante homogêneas, efetuaram-se as análises estatísticas sem qualquer transformação dos dados, encontrando-se os resultados no quadro 1. A análise da variância revelou diferenças altamente significativas entre os grupos, notadamente entre o que compreendia plantas normais e os que apresentavam notas 3 e 4 . Tendo em vista a tendência de queda contínua na produção, em função da intensidade dos sintomas, efetuou-se análise de regressão, com os seguintes resultados:

\begin{tabular}{lcrrc} 
F.V. & G.L. & Q.M. & \multicolumn{1}{c}{$\mathrm{F}^{*}$} & $\mathrm{r}^{2}$ \\
Grupos por sintoma & 3 & 4086,78 & $4,63^{* *}$ & - \\
Regressão linear & 1 & 12211,92 & $13,83^{* *}$ & 0,996 \\
Devios da regressão & 2 & 24,21 & 0,03 & -
\end{tabular}

Por meio da equação da regressão $\mathrm{Y}=98,3150$ $-13,7791 \mathrm{X}$, calcularam-se as médias esperadas e as reduções previstas na produção, nos diversos grupos de plantas afetadas.

O procedimento adotado para marcação de plantas baseou-se em observações prévias sobre a existência da gradação considerada de sintomas e, principalmente, no fato de não se notar processo evolutivo de um para outro desses estados, após a classificação das plantas afetadas. Esses pressupostos foram confirmados neste trabalho, quer pela observação das plantas por ocasião da colheita, quer pelos resultados de produção. Se, de fato, for assim, o virtual dano, em cada planta, ressal-

Quadro 1. Produções de algodão em caroço determinadas em plantas com diferentes intensidades da anormalidade "murchamento avermelhado" em Tatuí (SP) no ano agrícola 1993/94

\begin{tabular}{ccccc}
\hline \multirow{2}{*}{ Sintomas $\left(^{1}\right)$} & \multicolumn{2}{c}{ Produção média } & $\begin{array}{c}\text { Perdas } \\
\text { médias }\end{array}$ \\
\cline { 2 - 4 } & Obtida & Esperada Erro-Padrão & gsperadas \\
\cline { 2 - 4 } 1 & $84,2 \mathrm{a}^{(2)}$ & 84,5 & 8,2 & \\
\hline 2 & $70,6 \mathrm{ab}$ & 70,8 & 8,4 & 16,3 \\
3 & $58,6 \mathrm{bc}$ & 57,0 & 7,6 & 32,6 \\
4 & $42,2 \mathrm{c}$ & 43,2 & 6,5 & 48,9 \\
\hline
\end{tabular}

(1) Grau dos sintomas em escala crescente segundo a severidade (nota 1 = sem sintomas). $\quad\left({ }^{2}\right)$ Médias comparadas pelo teste de Duncan a $5 \%$. 
vadas as diferenças de caráter genético e variaçõcs de outra natureza, seria determinado por uma "carga" (impacto ou intensidade de ação recebida e já decisiva) do agente causal ou do eventual transmissor, podendo, portanto, ser estimado poucos dias após o aparecimento dos principais sintomas.

Do ponto de vista prático, isso poderia contribuir para previsões e, conseqüentemente, tomadas de decisão nas Iavouras atingidas. No campo científico, pode fundamentar método de avaliação de genótipos ou de outros tratamentos, com base na atribuição de notas, planta a planta, nas parcelas experimentais.

Quanto à aventada recuperação de plantas, se, por isso, for entendida a reforma ou aparente normalização da folhagem naquelas com sintomas, pelo menos a que se observou neste trabalho não foi suficiente para impedir as perdas na produção.

Ainda com respeito às perdas, os resultados não permitem estimá-las no nível de cultura, pois isso exigiria a determinação da proporção de plantas atacadas, em cada categoria, incluindo as que secam ou morrem. O que se pode adiantar é que tais dados são muito variáveis, tendo os autores observado, em outras localidades, desde glebas com incidência irrelevante até áreas com mais de $70 \%$ de plantas afetadas. Nestas, as plantas que secaram totalmente podem representar até um terço do total atacado e também é alta a freqüência daquelas com sintomas graves, como as de nota 4 , neste trabalho.
Assinale-se, todavia, que essas observações e resultados são válidos para a variedade IAC 20 , que se mostrou sensível a essa anormalidade em comparação com outros genótipos $\left({ }^{5}\right)$. Além disso, tal severidade pode ter decorrido de condições climáticas adversas, principalmente deficiência hídrica e altas temperaturas, que ocorreram em certo período desse ano agrícola.

Finalmente, deve-se registrar que anomalia semelhante ocorreu há alguns anos na Argentina, presumivelmente devida a vírus, transmitido por pulgão (Follin \& Campagnac, 1981). Caso se trate do mesmo problema, é útil assinalar que esses autores determinaram, em plantas atacadas, perdas de $68,5 \%$ na produção de algodão.

\section{REFERÊNCIAS BIBLIOGRÁFICAS}

COSTA,A.S. \& SAUER,H.G.F. Vermelhão do algodoeiro. Bragantia, Campinas, 13:237-247, 1954.

FOLLIN,J.C. \& CAMPAGNAC, N. Une maladie nouvelle du cotonier, présumée d'origine virale observée en Argentine. Coton et Fibres Tropicales, Montpellier, 36(4):313-317, 1981.

$\left({ }^{5}\right)$ Seção de Algodão, Instituto Agronômico, dados não publicados de trabalhos em andamento. 